\title{
(De)Composições do corpo físico \\ e social: a emergência do zumbi na ficção norte-americana contemporânea
}

Anderson Soares Gomes (UFRRJ)

Recebido 5 ago.2013/Aprovado 25 mar. 2014

\section{Resumo}

Um dos mais populares monstros do período contemporâneo, o zumbi se configura como significante privilegiado para captar as ansiedades do início do século XXI. Surgido nas narrativas de viagem de exploradores do Haiti no início do século XX, e depois adquirindo status de principal criatura do cinema de horror da atualidade, o zumbi vem servindo como alegoria para autores da literatura norte-americana tematizarem discussões sobre os limites da civilização, do corpo, e da própria noção de self. O presente trabalho se concentra em dois romances essenciais para melhor compreender o zumbi como símbolo da (de) composição do mundo contemporâneo. O primeiroéZone One, de Colson Whitehead, que mostra a tentativa de reconstrução da cidade de Nova York após a infestação da cidade pelas criaturas. O romance também apresenta uma variação bastante peculiar e complexa do zumbi: o straggler. A segunda obra aqui discutida é Guerra Mundial Z, de Max Brooks, que traça um mosaico de personagens e narra os acontecimentos de uma guerra con tra zumbis que praticamente extinguiu a humanidade. Os dois romances discutem, em suas narrativas, como o zumbi problematiza noções de alteridade por ser uma criatura despida de subjetividade, mas que ainda assim preserva traços humanos. Além disso, os mortos-vivos servem como exemplo máximo para o conceito de "estranho" (unheimlich), como analisado por Freud. Assim sendo, este trabalho pretende investigar a ascensão do zumbi como metáfora do momento atual na literatura norte-americana contemporânea e discutir como esse monstro tão assustador serve como representação do zeitgeist deste início de século.

Palavras-chave: zumbi; monstro; literatura norte-americana contemporânea. 
Espaço ontológico da ruína e da morte, o zumbi é o monstro contemporâneo por excelência. Surgido nas narrativas de viagem do início do século XX e depois adquirindo sobrevida (em mais de um sentido) no cinema independente norte-americano da década de 1960, o zumbi atinge proeminência inegável no mundo pós-11/09 para representar, de maneira avassaladora, as angústias tanto individuais quanto sociais causadas por uma decomposição anárquica das tradições humanistas.

Sendo um dos mais populares monstros do início do século XXI - com presença massiva em filmes, romances, histórias em quadrinhos, videogames e até mesmo livros infantis - o zumbi curiosamente escapa a uma definição precisa. Mesmo não havendo muita dificuldade em identificar um zumbi (caracterizado de maneira tradicional por sua pele pálida, olhos sem vida e andar arrastado), dizer o que um zumbi realmente é consiste em tarefa muito mais complexa. Isso se dá especialmente porque o zumbi surge como figura máxima da negação e do caos, sendo uma representação da ausência total: sem alma, sem consciência, sem passado, sem futuro, sem vida. O zumbi é apenas corpo. Um corpo, porém, marcado por uma negação completa. Definir um zumbi começa exatamente pelo que ele não é.

A própria etimologia do termo "zumbi" é incerta - a palavra pode ser uma variação do termo angolano nzúmbe, significando "espírito ou fantasma" (BISHOP, 2010, p.47), ou do nome Nzambi, figura mítica que as tribos da região próxima ao rio Congo acreditavam vigiar suas vidas (CHRISTIE \& LAURO, 2011, p.50). Ou pode vir até mesmo do francês sombre (RUSSELL, 2010, p.20). A palavra provavelmente chegou junto com os escravos africanos ao Haiti, onde recebeu as variações zobi e depois zombi (BISHOP, 2010, p.47). Na língua inglesa, a palavra zombie aparece pela primeira vez via formação do português brasileiro: de acordo com o Oxford English Dictionary, o termo foi originalmente utilizado na obra História do Brasil, de Robert Southey, no qual o autor diz que zumbi é sinônimo de "diabo". Curiosamente, a edição do livro de Southey presente na British Library pertenceu ao poeta e crítico do século XIX Samuel Taylor Coleridge, que anotou à margem do texto que a definição de zumbi dada por Southey estava incorreta - apesar de não dizer a razão. (RUSSELL, 2010, p.23) Já no momento de sua concepção, o zumbi escapava a definições precisas, mesmo que analisado por um dos maiores escritores românticos da Inglaterra. Afinal de contas, Coleridge, que em The Rime of the Ancient Mariner narra uma partida de dados entre a "Morte" e a "Morte em Vida", certamente é uma voz a ser respeitada quando se trata de mortos-vivos. 
Ainda que existam em outras regiões histórias de figuras mortas que voltam a caminhar sobre a Terra, é no Haiti onde surge o primeiro conceito estabelecido de zumbi. Descrito de forma breve em um artigo de 1889 da Harper's Magazine intitulado "The Country of the Comers-Back", e depois de maneira mais articulada pelo jornalista norte-americano William Seabrook em 1929 no livro The Magic Island, o zumbi se constitui originalmente como uma criatura relacionada à magia negra. Seabrook descreve o zumbi como "um cadáver humano sem alma, ainda morto, mas tirado do túmulo e mantido por feitiçaria com um semblante mecânico de vida - é um corpo que se faz andar e agir e mexer como se estivesse vivo." (SEABROOK, 1989, p.94, trad. livre). No contexto haitiano, os cadáveres eram magicamente retirados dos túmulos para trabalhar nas lavouras como escravos. Nos EUA, esta primeira acepção do zumbi vinda do Haiti adquire grande popularidade com o filme White Zombie, de 1932, em que um "mestre zumbi" (vivido por Bela Lugosi) usa de um tipo de hipnotismo com o intuito de conseguir trabalhadores para a plantação de um latifundiário no Haiti.

Desde White Zombie, outros filmes tomaram uso da figura aterrorizante do zumbi, geralmente com pouca ou nenhuma alteração com relação a suas origens haitianas, ou seja, em um contexto agrário, geralmente caribenho e subdesenvolvido, um "mestre zumbi" enfeitiça pessoas para servirem como seus escravos. Esse paradigma sofre alterações fundamentais com o lançamento, em 1968, do filme A Noite dos Mortos-Vivos, de George Romero. Considerado o criador do conceito moderno de zumbi, Romero mistura de forma original a versão haitiana do zumbi com elementos do romance I Am Legend, de Richard Matheson, para criar sua própria variação do que é um morto-vivo. Ao tradicional estado de transe e andar lento, Romero adiciona três traços essenciais que marcam a versão moderna (e até hoje, a mais popular) do que seria um zumbi: eles são autônomos, dispensando a necessidade de um feiticeiro que os comande como no zumbi haitiano; eles são canibais, possuindo um desejo incessante de consumir carne humana; e eles são infecciosos, pois podem transformar seres humanos em zumbis através de mordidas (MOREMAN \& RUSHTON, 2011, p.152).

A configuração moderna do zumbi estabelecida por Romero apenas começa a sofrer alterações significativas no século XXI, com o lançamento em 2002 do filme Extermínio, de Danny Boyle. Essa produção não apresenta zumbis em sua (falta de) natureza mais fundamental, que é o fato de ser um morto-vivo. Na verdade, as criaturas de Extermínio são indivíduos infectados por um vírus da raiva extremamente potente, que as torna ágeis e lhes dá um poder de destruição ainda mais devastador que o zumbi de Romero. Partindo dos critérios bastante influentes do filme de Boyle, pode-se dizer que o zumbi contemporâneo é veloz, tem 
uma origem marcadamente científico-biológica e, especialmente, não está necessariamente morto.

O zumbi constitui o mais recente exemplo arquetípico de monstro e, como tal, é moldado pela mais moderna das grandes artes: o cinema. Diferente de outros arquétipos de monstro (o vampiro, o fantasma, a criatura de Frankenstein), que se consolidam no século XIX através da mais popular produção artística da época, a literatura, o zumbi ilustra uma mudança paradigmática para o cinema como instrumento mais poderoso na regulação dos critérios do que é aterrorizante. Enquanto o vampiro precisa do discurso falado para seduzir suas vítimas e a criatura de Victor Frankenstein aprendeu a falar através da leitura de clássicos, o zumbi prescinde da fala e da escrita: ele apenas olha e devora. $\mathrm{O}$ zumbi é apenas imagem, o mais cinematográfico dos monstros.

Se os mortos-vivos já têm certa tradição no cinema, na literatura começam a surgir autores que usam o zumbi como instrumento para tematizar as ansiedades e contradições da sociedade contemporânea. $\mathrm{O}$ zumbi parece ter sido aceito como metáfora privilegiada para representar as ameaças e medos mais presentes no século XXI: mais da metade de todos os filmes sobre zumbis foram produzidos após o 11 de setembro de 2001. Se no cinema ainda hoje o zumbi parece estar relacionado a filmes B, custos baratos e ao escatológico, a literatura usa o mais contemporâneo dos monstros como ponto de partida para uma discussão sobre a dissolução de subjetividades em meio a um mundo pós-ideológico.

O meio ficcional contemporâneo vem presenciando cada vez mais uma aproximação entre a genre fiction, i.e. literatura de temáticas características e apelo mais popular como ficção científica e horror, e um gosto literário mais sofisticado. Alguns escritores reconhecidos como os mais importantes do momento literário atual vêm se aventurando constantemente por terrenos fantasiosos e/ou futuristas antes apenas explorados pela genre fiction: Kazuo Ishiguro (Não me abandone jamais), Philip Roth (Complô contra a América), Haruki Murakami (1Q84), Cormac McCarthy (A estrada), Michael Chabon (As incriveis aventuras de Kavalier e Clay) e Junot Díaz (A fantástica vida breve de Oscar Wao) são alguns exemplos. Como afirma o escritor Benjamin Percy, ele próprio representante dessa categoria de ficcionistas:

As grandes histórias de horror sempre lidaram com as ansiedades culturais de seu tempo. Dê uma olhada em Frankenstein e a revolução industrial. Ou Drácula e a hipocrisia vitoriana. [...] E se você olhar para o que tem estado nas prateleiras das livrarias desde o 11 de setembro, vai ver uma abundância de narrativas apocalípticas e pós-apocalípticas. Todas elas têm a ver com o nosso medo de doenças, nosso medo da devastação

Cf. Zombies: A Living History. DVD. History Channel. do meio ambiente, nosso medo da aniquilação nuclear. Talvez porque o fim do mundo nunca parecesse tão provável. (Citado em FASSLER, 2011, trad. livre) 
Sendo o zumbi uma das mais reconhecidas figuras de metaforização pós-apocalíptica da contemporaneidade, ele se torna terreno fértil para ser explorado ficcionalmente. O primeiro escritor vencedor de prêmios literários e considerado expoente da nova literatura norte-americana a lidar com o tema é Colson Whitehead, em seu romance Zone One, publicado em 2011. Com uma narrativa concisa que se passa em três dias, o romance mostra uma Nova York devastada por uma pandemia zumbi que aniquilou praticamente toda a cidade. O protagonista Mark Spitz é um dos membros da Unidade de Varredura, responsável pela localização e extermínio de zumbis para que a cidade possa novamente se tornar habitável. Entremeado por flashbacks, o enredo de Zone One se desenvolve de maneira fluida, no qual o desenrolar da trama se dá menos por uma busca de coesão narrativa e mais por uma sucessão de episódios que constrói uma cartografia de sentidos.

Whitehead explora em Zone One o efeito fundamental da emergência do zumbi na esfera humana: a total destruição do edifício coletivo e progressista da humanidade para lançar os indivíduos em uma era de trevas quando a própria noção de futuro se torna problematizada. Em outras palavras, o zumbi é a representação do apocalipse. É muito comum, inclusive, encontrar a expressão "apocalipse zumbi" para descrever histórias em que essas figuras se fazem presentes. $\mathrm{O}$ surgimento do zumbi em qualquer contexto pressupõe, portanto, o fim do mundo. Em sua origem bíblica, porém, o apocalipse não significa apenas a aniquilação da humanidade. O conceito de apocalipse - como já sugere o termo referente em inglês, revelation - também expõe uma maneira de interpretar o destino através da forma em que ele se mostra para o homem. A figura do monstro parece ser sintomática dessa revelação de um fim para a humanidade, já que em sua própria raiz etimológica, o monstro é aquele que demonstra algo (monstrere) ou serve como alerta de algo no porvir (monere). Não só en-carnando o fim dos tempos, mas também devorando a carne, o zumbi crava seus dentes não apenas no tecido humano, mas também no tecido social, marcando o colapso da ordem natural.

Nova York é o local do fim dos tempos em Zone One. A cidade como descrita por Whitehead se configura como espaço do caos urbano, da multiplicidade opressiva e da apatia entrópica, tanto antes quanto depois do apocalipse zumbi. Os ecos do 11 de setembro, naturalmente, não escapam ao escritor. De todos os monstros que habitam o imaginário, nenhum é mais adaptável que o zumbi. Seu corpo em decomposição serve como receptáculo das mais diferentes incursões metafóricas. Como afirma Marc Leverette, "é o vazio simbólico que dá a eles sua força; as pessoas podem preenchê-lo com qualquer medo que desejarem" (LEVERETTE, 2008, p.203, trad. livre). O zumbi, portanto, pode ser lido como um significante móvel na definição de Tony Bennett e Janet Woollacoot (1987), ou seja, "um símbolo cultural que muda de 
sentido através do tempo e em diferentes contextos" (MOREMAN \& RUSHTON, 2011, p.151).

Com seus prédios em ruínas e destruição em larga escala, a Nova York de Zone One partilha diversas características com a Nova York de setembro de 2001. A sinergia entre a cidade e os zumbis como arquitetada por Whitehead é tão completa que a discussão sobre a construção de uma alegoria zumbi pós-11/09 se torna tão relevante quanto narrar a reconstrução de Nova York pós-apocalipse zumbi. Tendo terror como sua raiz vocabular, o terrorismo tem seu lugar estabelecido como principal medo em escala global, sendo terreno fértil para proliferação de monstros, em especial nos EUA. O zumbi, mesmo com seu andar lento, é um significado móvel e também fecundo para (re)/(des-)construções metafóricas do terrorismo. Como afirma Warren St. John, em artigo para The New York Times sobre a crescente popularidade dos zumbis no século XXI,

Não é necessário ir muito longe para ver o paralelo entre zumbis e terroristas anônimos que buscam converter outros dentro da sociedade para sua causa mortal. O medo de que qualquer um pode ser um homem-bomba ou um sequestrador é paralelo ao tropo comum de filmes de zumbi, em que pessoas saudáveis são zumbificadas pelo contato com outros zumbis e se tornam assassinas. (ST. JOHN, 2011, trad. livre.)

Colson Whitehead, porém, vai além da mera associação entre zumbis e terroristas. De forma extremamente irônica, a narrativa estabelece relações bastante claras entre o comportamento dos nova-iorquinos pré-"apocalipse zumbi" e os zumbis que posteriormente levarão a cidade à ruína. É como se a força caótica do zumbi já estivesse encubada em cada indivíduo, para depois culminar em uma reação em larga escala na qual uma fúria niilista eclode, espalhando um sentimento permanente de ausência de sentido. A cidade de Nova York é descrita da seguinte maneira:

A Nova York morta era bem parecida com a Nova York em vida. Ainda era muito difícil pegar um táxi, por exemplo. A principal diferença é que tinha menos pessoas. Era mais fácil caminhar pelas ruas. [...] Os restaurantes da moda sempre tinham uma ótima mesa disponível, mesmo que não atualizassem o cardápio desde que a raça humana tinha sido peneirada. (WHITEHEAD, 2011, p.80, trad. livre)

Se a cidade aparentemente permanecia a mesma, vemos então que o que distingue a Nova York pós-zumbis é o número de pessoas nas ruas. Porém, o romance sinaliza que, embora essa mudança quantitativa tenha sido marcante, em termos de qualidade, os novos residentes da cidade não são tão diferentes assim dos antigos habitantes. Os vivos e os mortos-vivos têm bastante em comum. Em primeiro lugar, porque os zumbis, mesmo em sua decrepitude e canibalismo, são os mais humanos dos monstros. 
Existe uma tensão ontológica na fronteira que separa o zumbi do humano: o que um dia já foi vivo não é mais, o limite entre o eu e o outro é de uma mordida. Diferente do vampiro, porém, eles podem transformar todo(s) o(s) eu(s) em outro(s) e, com isso, levar ao fim da civilização. A decomposição do corpo físico do zumbi é sinédoque da decomposição do corpo social.

Em segundo lugar, os zumbis também são representativos de um embaçamento ontológico, pois são os únicos monstros que detêm traços físicos determinantes que remetem ao período em que ainda eram humanos. Diferentemente dos fantasmas, que são alma pura sem corpo, os zumbis são puro corpo sem alma. Daí um dos tropos fundamentais das narrativas de zumbi: a indefinição entre quem (ou o que) é zumbi e quem não é. O zumbi é o emblema da ausência de subjetividade, é a nulidade perfeita. É até mesmo possível dizer que é impossível se tornar um zumbi, pois o que quer que ele seja, não é você. O que pode ser lido como traço humano e/ou reconhecível em um zumbi (um amigo, um vizinho, um parente) é apenas a subjetividade do observador lançada de volta para ele. O zumbi é a superfície refletora da morte. Mark Spitz, o protagonista de Zone One, é tomado por essa sensação de familiaridade:

De vez em quando acontecia dele reconhecer algo nesses monstros, eles pareciam com alguém que ele tinha conhecido ou amado. Parceiro de trabalho de laboratório da oitava série ou caixa magricelo do mercadinho, namorada da faculdade de primeiro ano. Tio. [...] Essas coisas devem ter sido pessoas que ele conheceu, não tão bem ou que poderia ter conhecido melhor, eles eram a família de alguém e eles mereciam ser libertos de suas sentenças de sangue. (WHITEHEAD, 2011, p.19, trad. livre)

Diferentemente das narrativas de zumbi tradicional, nas quais indivíduos hesitam em exterminar zumbis quando são tomados por uma certa sensação de familiaridade ao observá-los, Spitz vê nisso uma atitude de piedade e libertação, exatamente porque eles já foram humanos e estão condenados a sua presente condição de morto-vivo.

Finalmente, as fronteiras entre o humano e o zumbi em Zone One são ainda mais problematizadas quando, em diversos momentos da narrativa, se articula a noção de que grande parte da população de Nova York já era formada por mortos-vivos antes mesmo do "apocalipse zumbi". Whitehead, escrevendo sob o pano de fundo da recessão econômica de 2009 e do movimento Occupy, vê nos desempregados, funcionários de grandes corporações e cidadãos insatisfeitos um processo de zumbificação que prenuncia o fim dos tempos. É uma Revelation que serve de prólogo para o apocalipse. Ao ver um solitário skel (um dos vários nomes pelos quais os zumbis são reconhecidos no romance) vagando solitário, 
Mark Spitz divaga sobre sua relação com os indivíduos que costumava ver pela cidade:

Não era mais um skel, mas a versão de algo que precedia as ansiedades. Agora era um daqueles empresários arruinados ou demitidos que fingiam ir para o escritório por causa da família [...] A cidade já tinha há algum tempo carregado sua própria praga. Sua infecção havia convertido essa criatura em um membro do seu grupo de perdedores, em mais um de seus falidos e desiludidos [...] Ele os havia visto caminhando pelas calçadas em sua tristeza [...] Essa criatura diante deles era o homem no ônibus que ninguém sentava perto [...] a coisa que os novos funcionários diziam que nunca iriam se tornar mas é claro que era o que acontecia com alguns deles. (WHITEHEAD, 2011, p.149, trad. livre)

Apesar da narrativa de Zone One se recusar a fornecer uma origem específica para o surgimento dos zumbis per se, nota-se que a praga tem relação com a derrocada do próprio sentido de individualidade, em consequência, especialmente, do ethos de desesperança e torpor que toma conta da sociedade norte-americana na primeira década do século XXI. Partindo dessa premissa, vemos que a humanidade dos habitantes de Nova York vai se esvaindo até que são engolidos pelo vazio completo da morte. No contexto do apocalipse zumbi, ser pós-humano é ser post-mortem.

Assim sendo, um dos pontos centrais metaforizados por Whitehead é de que os zumbis já existem e, de certa forma, já caminham por entre as ruínas de uma ordem sócio-econômica em desarranjo. $\mathrm{Ou}$, como afirmou de maneira célebre o protagonista do filme Madrugada dos Mortos (1978), de George Romero, referindo-se aos zumbis: "Eles somos nós". Tomando como partida o pensamento de Hegel sobre a formação dos hábitos sociais, o filósofo Slavoj Žižek reforça essa aproximação entre humanos e zumbis:

No nível mais elementar de nossa identidade humana, nós todos somos zumbis, e nossas "nobres" e "livres" atividades humanas só podem acontecer à medida que são fundadas em um funcionamento confiável de nossos hábitos-zumbi: ser-um-zumbi é um nível-zero de humanidade. O choque de encontrar um zumbi não é o choque de encontrar uma entidade estrangeira, mas o choque de ser confrontado pela negação da fundação de nossa própria humanidade. (ZIZEK apud BOLUK \& LENZ, 2011, p. 116, trad. livre)

Em Zone One, a ideia de "nível-zero de humanidade" mencionada por Žižek é corporificada na figura do straggler, uma espécie de variação do zumbi tradicional. Enquanto os skels, como chamados no romance, funcionam seguindo a taxonomia de zumbis delineada por George Romero - canibal, caminhando de forma lenta mas implacável, desprovido de consciência - os stragglers são figuras que permanecem imóveis, em estado catatônico, estacionadas em locais específicos que provavelmente 
tiveram significado quando elas ainda tinham algum sentido de volição. Assim, o antigo psicanalista continuava sentado em sua poltrona esperando o paciente que nunca viria; o vendedor da loja de sapatos permanecia agachado olhando para o pé de um cliente imaginário; um homem olhava para a vitrine tentando ajustar, em seu reflexo, óculos imaginários. Os stragglers são "uma sucessão de tableaux imponderáveis", um "exército de manequins" (WHITEHEAD, 2011, p.60), imobilizados em atividades eternas que, de certa forma, resumem em um momento único o tipo de vida que levavam. Os stragglers, mais do que os zumbis tradicionais, simbolizam traços residuais de humanidade.

Uma das funções da unidade militar da qual Mark Spitz faz parte é eliminar os stragglers. Mesmo não apresentando nenhuma ameaça aparente, é função dos soldados "varrer" a cidade para um futuro plano de repovoamento. A forma de se eliminar um straggler era a mesma de um skel - atirando na cabeça. Spitz geralmente se sentia desconfortável em exterminar um straggler, a não ser que fosse por razões que diz ser de "princípios" - quando, por exemplo, elimina um deles que permanecia em um restaurante fast food na posição de fritar hambúrgueres. Já outros soldados possuem uma espécie de prazer mórbido no extermínio de stragglers, chegando a fazer disso uma forma de entretenimento. Há o jogo "Defina o Straggler", em que eles tentam descobrir como o straggler chegou àquele local específico e qual a relação do mesmo com sua vida prévia. Outro jogo bastante popular se chama "Nomeie Essa Mancha!", em que, após atirar na cabeça de um straggler, os soldados discutiam com o que a mancha de sangue na parede ou no chão se parecia.

O straggler, como variação do zumbi, leva ao extremo a problematização do conceito de alteridade, um dos traços definidores de figuras monstruosas. As narrativas de horror geralmente se caracterizam pelo medo do Outro e da subjugação pelo Outro dois dos principais temas das narrativas de horror, especialmente se consideramos a literatura gótica do século XIX (BISHOP, 2010, p.96). O straggler, assim como o zumbi da variação de Romero, cria uma tensão entre o eu (self) e o Outro, pela qual uma ansiedade torna-se latente a partir do momento em que as duas categorias não são tão distintas assim.

Os stragglers, diferentemente dos skels, são figuras cuja ausência de movimento ilustra ainda mais claramente sua ausência de consciência, de desejo. Os skels, ou zumbis tradicionais, se é que possuem algum desejo, é o de devorar os humanos - ao ser atacado por um zumbi, o indivíduo tem duas opções: ou se torna um morto, ou morto-vivo. Os stragglers, por outro lado, não possuem essa voracidade canibal. Eles se parecem exatamente comos seres humanos, exceto em sua ausência de subjetividade, análoga à sua ausência de movimento. Por esse motivo, os stragglers, em vários momentos de Zone One, podem ser identificados 
mais diretamente com os seres humanos do que com os próprios skels, ou seja, os stragglers não seriam uma variação do zumbi, mas do indivíduo racional. Mark Spitz reconhece isso quando comenta que, enquanto os skels são referidos como "aquilo" ou "coisa", os stragglers recebem pronomes masculinos e femininos (WHITEHEAD, 2011, p.102).

A razão pela qual Spitz se sente enojado pelo espetáculo mórbido do extermínio descontraído dos stragglers não é apenas pelo sadismo dos soldados. Também é pelo reconhecimento de que o straggler não simboliza um Outro completo, mas um eu (self) em potencial. Em um episódio em particular, Mark Spitz tenta dissuadir seus companheiros a eliminarem um straggler (a quem nomeiam "Ned, o cara da Xerox", por estar paralisado em frente a uma máquina de fotocópias): "E se deixarmos ele ficar? [...] Ele não está maltratando ninguém. Olhem pra essa sala. Essa deve ser a sala mais deprimente da cidade toda." (WHITEHEAD, 2011, p.102). A empatia de Spitz por "Ned", porém, não é partilhada pelos outros, que o eliminam com um tiro na cabeça. A cena se conclui com um comentário que sintetiza a aproximação entre os stragglers e os indivíduos zumbificados que habitam os EUA na contemporaneidade: "Se eles estivessem brincando de Nomeie Essa Mancha!, Mark Spitz teria dito, América do Norte." (WHITEHEAD, 2011, p.103).

O medo do Outro e do controle pelo Outro, quando se trata de zumbis (ou stragglers), também se consolida de maneira insidiosa através de um desdobramento aterrorizante: o medo de ser o Outro. Frente a um monstro irracional e representativo da morte como o zumbi, somos confrontados com o medo de que "sejamos pouco mais do que animais, preocupados apenas com nosso apetite." (BISHOP, 2010, p.119). Esta proximidade entre o eu (self) e o Outro no zumbi ilustra de forma clara o que Sigmund Freud categorizou como o unheimlich, uncanny ou estranho, em influente artigo de mesmo nome. Freud chama de estranho "aquela classe de figuras aterrorizantes que remete a algo previamente conhecido por nós, que já foi bastante familiar." (FREUD, 2003, p.4). O pai da psicanálise funda o conceito de estranho a partir de dois outros estudos que encontram eco não apenas na figura do zumbi contemporâneo, mas também nos stragglers de Zone One.

O primeiro deles é o conceito de unheimlich como estabelecido pelo psicólogo E. Jentsch, para quem o estranho lança dúvida sobre a possibilidade de um ser aparentemente animado não estar realmente vivo; ou de um objeto sem vida estar, de fato, animado (cf. JENTSCH apud FREUD, 2003, p.5). Essa fronteira difusa entre ser animado e ser vivo está no cerne de qualquer narrativa sobre zumbis. Um morto-vivo, como sua própria nomeação oximorônica deixa ver, é o elemento sem vida que de-monstra sua animação, é o walking dead. O elemento estranho dos stragglers é ainda mais complexo: mesmo sendo aparentemente sem vida e imóveis, um 
deles ataca um soldado ao final de Zone One, prenunciando um despertar dessas criaturas e uma nova ameaça.

A segunda ideia importante na definição de estranho vem do filósofo Schelling, para quem "unheimlich é o nome para tudo que deveria ter permanecido [...] escondido e secreto e se tornou visível" (SCHELLING apud FREUD, 2003, p.4). Os zumbis são, antes de mais nada, cadáveres. Como corpos sem vida, são separados da esfera social, geralmente através de alguma cerimônia religiosa ou solene. O que antes era familiar (heimlich), agora se torna estranho (unheimlich) e por isso tem que ser escondido, isolado, pois sua própria presença é um risco para aqueles que ainda vivem (mau-cheiro e doenças em decorrência da putrefação). $O$ zumbi, portanto, ao se recusar à sua condição de confinamento, torna visível o medo último da humanidade: a morte.

O conceito de estranho como estabelecido por Freud faz mais do que descrever o zumbi - na verdade, o estranho sintetiza a resposta da humanidade aos aspectos que lhe causam desconforto e medo exatamente por serem familiares. $E$ ao se verem forçados a terem que decapitar ou atirar na cabeça daqueles que até pouco tempo atrás tinham importância em sua vida, os indivíduos veem surgir em si um lado animalesco e violento que desconheciam. Da mesma forma que os zumbis se erguem da terra para espalhar o caos em larga escala, também se ergue das profundezas de cada ser humano uma força análoga de matança e destruição. Em Zone One, Mark Spitz tem um momento de epifania em que reconhece seu papel na Nova York devastada e, por conseguinte, da humanidade em geral dentro de um contexto apocalíptico:

As pessoas da cidade, obviamente, eram os monstros de verdade. Era o objetivo da praga revelar nossos familiares, amigos e vizinhos como as criaturas que eles sempre foram. E o que a praga mostrou que ele era? Mark Spitz sobreviveu enquanto a humanidade era eliminada gradualmente. Uma parte dele prosperava no fim do mundo. Como explicar: ele tinha uma queda pelo apocalipse. A praga tocava a todos, contato sanguíneo ou não. Os assassinos escondidos, estupradores em potencial e fascistas latentes estavam agora livres para expressar suas naturezas brutais [...] Eu sempre fui assim. Agora sou mais como eu sou. (WHITEHEAD, 2011, p.245, trad. livre)

Quando a própria diferença entre vida e morte se torna intangível, a monstruosidade humana vem à tona. Os zumbis são corpos mortos que devoram os vivos, eles são a força entrópica que suga a vida para transformá-la em morte. Mas os humanos, mesmo que ainda detentores de sua subjetividade, veem no apocalipse a válvula de escape para sua fome destrutiva - de forma similar ao zumbi. A praga, como afirma Mark Spitz, prescinde de contato sanguíneo para transformar qualquer indivíduo em monstro. 
Zone One é um romance que aborda o apocalipse zumbi a partir de um local específico (Nova York), concentrando-se nas ações e reações de um personagem central (Mark Spitz). Existem outros romances contemporâneos, porém, que lidam com a temática dos mortos-vivos em escala global e seus múltiplos desdobramentos. Destes, o mais denso e emblemático é Guerra Mundial Z: Uma História Oral da Guerra Zumbi, de Max Brooks. O autor, que já havia explorado de maneira mais humorística o topos do fim do mundo em Guia de Sobrevivência Zumbi, de 2003, lança seu olhar crítico, com uma abordagem realista para os terríveis efeitos de uma guerra zumbi que atinge todo o planeta.

Brooks explicita em Guerra Mundial Z uma diferença tipológica entre o zumbi e outros tipos de criaturas aterrorizantes. $\mathrm{O}$ morto-vivo, ao mesmo tempo em que é um monstro, também é um inimigo bastante prático. Não se fala em táticas de batalha e manobras militares contra vampiros, por exemplo. O zumbi é o catalizador de uma força caótica que almeja o fim da própria civilização. Porém, ao contrário de figuras do Outro tradicional, ele é uma ameaça externa, mas também interna.

Representações mais tradicionais de zumbis no cinema, literatura, histórias em quadrinhos e videogames geralmente estabelecem uma macro-narrativa de calamidade coletiva (o apocalipse zumbi) para se concentrarem essencialmente em narrativas de pequenos grupos de sobreviventes em um espaço delimitado: fazendas, casebres, pequenas vilas e até mesmo shopping centers (como no clássico Madrugada dos Mortos de George Romero). Em Guerra Mundial Z, por outro lado, Brooks faz uso da estratégia da entrevista para, em um momento histórico pós-guerra, dar voz a personagens (do vice-presidente americano ao nerd japonês) que vão relatar suas experiências. O escopo é ao mesmo tempo vasto e particular no qual "as micro e as macro-narrativas partilham de uma superestrutura similar." (MOREMAN \& RUSHTON, 2011, p.184, trad. livre).

Guerra Mundial Z é inspirado notadamente por duas fontes centrais. Em primeiro lugar, os filmes de George Romero, a quem Brooks agradece particularmente. Os zumbis do romance pertencem ao estilo que foi criado pelo mestre do cinema de horror dos anos de 1960 e 1970, especialmente por exibir as características centrais delineadas por Romero: o andar lento, a infecção pela mordida e o canibalismo.

A segunda obra na qual grande parte da estrutura de Guerra Mundial Z se inspira é The Good War, de Studs Terkel. The Good War é um popular livro de história sobre a Segunda Guerra Mundial que traça os principais eventos do conflito se utilizando de relatos individuais. É a partir desse ponto de vista pessoal que vários dos sobreviventes da guerra contra os zumbis vão narrar sua experiência, que Brooks organizará o romance em tom quase que memorialístico. 
A moldura narrativa de Guerra Mundial Z se estabelece através da compilação de histórias orais feitas pelo narrador/ entrevistador, um alto funcionário da Organização das Nações Unidas (ONU). Seu objetivo é conceber um texto que trate de maneira mais particular os eventos ocorridos durante a guerra contra os zumbis (chamada, além de "Guerra Mundial Z", de "A Idade das Trevas" e "A Crise", entre outros nomes), já que o Relatório Oficial Pós-Guerra da Comissão da ONU é totalmente burocrático e exclui o significado emocional do conflito. Assim sendo, Brooks aproxima os possíveis leitores (ficcionais) desse relatório mais pessoal escrito pelo funcionário da ONU aos leitores (reais) do romance Guerra Mundial Z. Porém, enquanto os primeiros têm conhecimento prévio dos acontecimentos descritos, os últimos têm acesso aos eventos ocorridos apenas a partir da perspectiva altamente subjetiva dos personagens.

Guerra Mundial Z é dividido em nove capítulos, cada um deles descrevendo não apenas um momento específico da guerra, mas também a reação humana à emergência do zumbi. A primeira parte é introdutória, explicitando os objetivos desse novo e mais pessoal relatório; a segunda parte, "Alertas", lida com as primeiras aparições de zumbis em diferentes partes do mundo; "Culpa" trata da incredulidade e incompetência de funcionários de esferas governamentais em responder à ameaça zumbi, além de descrever as maneiras em que a posterior histeria tentou ser aproveitada financeiramente; "O Grande Pânico" relata como a população reagiu de forma instintiva à proliferação dos zumbis; "Virando o Jogo" se concentra nos primeiros planos bem-sucedidos de ataque contra os zumbis; "Frente de Batalha: EUA" aborda como os norte-americanos lidaram com o conflito; "Ao Redor do Mundo, e Acima" trata das perspectivas de diversos países para combater os zumbis, além do papel dos astronautas na Estação Espacial Internacional; "Guerra Total" descreve a investida final e vitoriosa dos humanos contra os zumbis; e finalmente, "Despedidas" retoma a fala de vários dos entrevistados para prever o futuro da humanidade pós-guerra zumbi.

Como a descrição dos capítulos acima atesta, Guerra Mundial $Z$ usa a ameaça zumbi como estratégia narrativa para discutir a própria natureza da humanidade e de que forma os indivíduos reagem a uma catástrofe que pode vir a extinguir toda a existência humana. Dessa forma, o zumbi se configura como um forte símbolo de mudança não apenas de destruição, mas também de renovação. As estruturas sociais jamais serão as mesmas depois da emergência dos mortos-vivos. No caso de Guerra Mundial Z, desde o princípio, sabemos que o final da história será a da vitória dos humanos contra os zumbis:

Ao contrário da maioria das mais niilistas histórias de zumbis, o apocalipse zumbi retratado pelo romance de Brooks termina 
de forma muito mais esperançosa - o mundo como os sobreviventes o conheciam terminou, mas os zumbis não venceram. Os sobreviventes sofridos estão reivindicando seus países - e contando suas histórias com suas próprias vozes [...] Nessa coleção de histórias orais dos indivíduos, a mais persistente reanimação não é a dos mortos, mas dos vivos" (CHRISTIE \& LAURO, 2011, p.189, trad. livre).

Mesmo com um final em tom otimista, o romance deixa claro, portanto, que as estruturas que sustentavam o mundo pré-zumbi foram alteradas por um contexto social e político que teve que surgir em uma realidade posterior à Guerra Mundial Z. A partir dessa perspectiva, mais do que discutir o pós-humano em uma sociedade infestada de zumbis, Guerra Mundial Z apresenta uma investigação sobre o efeito de um mundo pós-zumbi na humanidade.

Desde sua primeira aparição em narrativas de viagem e no cinema, o zumbi vem servindo como alegoria para ansiedades de caráter social e econômico. O próprio zumbi haitiano, como descrito por William Seabrook em The Magic Island, era concebido para trabalhar nas lavouras de cana de açúcar. Quando transposto para o cinema, esse zumbi de origem voodoo tem como grande vantagem ser mais do que um escravo - ele é praticamente uma máquina. "Eles trabalham de forma fiel. Não se preocupam em trabalhar por longas horas", diz o mestre zumbi vivido por Bela Lugosi em White Zombie. George Romero, mesmo criando posteriormente sua própria mitologia para os zumbis, preserva esse traço quase que marxista da descrição dos zumbis. O diretor afirma: “Os zumbis são os verdadeiros cidadãos de segunda-classe entre os monstros, e é por isso que eu gosto deles [...] O zumbi para mim sempre foi um tipo de monstro operário." (HERVEY, 2008, p.57)

Quando o zumbi chega aos EUA vindo do Haiti no final da década de 1920, ele tem a notável capacidade de absorver o zeitgeist da crise econômica de 1929 e o início da Grande Depressão. De certa forma, o zumbi preserva em si uma espécie de memória residual comum do período de escravidão no Haiti (SCOTT, 2007, p.46). Pela primeira vez em sua história, os norte-americanos sentiram claramente os males do capitalismo e o sentimento de impotência que ele provoca em momentos de crise. Há muito de zumbificação nas tristes imagens de desempregados em longas filas para conseguir um pão ou então na demorada e inútil espera por uma oportunidade de emprego. Quando George Romero denomina o shopping center como o locus perfeito para a invasão zumbi em Madrugada dos Mortos, é evidente a crítica mordaz ao sistema capitalista e ao consumismo que move a economia norte-americana - afinal de contas, não haveria muita diferença entre os compradores que vagam olhando as vitrines e zumbis. Éa partir dessa perspectiva crítica ao modelo capitalista que Deleuze e Guattari afirmam que "os zumbis são o único mito moderno, 
schizos mortificados bons para trabalhar e fáceis de serem controlados." (DELEUZE \& GUATTARI, 1983, p.335)

O embate entre zumbis e humanos em Guerra Mundial Z consiste em terreno fértil para críticas ao individualismo econômico, especialmente no EUA. Um dos melhores exemplos é o personagem Breckinridge "Breck" Scott, um oportunista que viu na epidemia zumbi uma oportunidade sem precedentes para lucrar. Breck declara seu ponto de vista com relação à economia:

Você entende de economia? Estou falando de capitalismo global, antes da guerra. Você sabe como funcionava? Eu não, e qualquer um que diga que entende está mentindo. Não existem regras, nenhum absoluto científico. Você ganha, você perde, é uma aposta cega. A única regra que fez sentido pra mim eu aprendi com um professor de história e não de economia, em Wharton. "Medo", ele costumava dizer, "medo é a mercadoria mais valiosa no universo" (BROOKS, 2006, p.54-55, trad. livre).

Com o intuito de capitalizar através do medo da população assim que surgem os primeiros surtos do que acreditavam ser um misterioso vírus da raiva, Breck cria uma suposta vacina - Phalanx - que divulga ter potencial preventivo contra a epidemia. O personagem faz uma fortuna e se torna um dos maiores empresários do país, até sua farsa ser descoberta e ele cair em desgraça e passar a viver exilado. Ao ser contestado sobre o Phalanx não ter valor preventivo nenhum, o personagem responde:

Não era mais a ideia de segurança. Era a ideia da ideia de segurança. [...] [A vacina] os protegia dos seus medos. Era tudo que eu estava vendendo. Por causa do Phalanx, o setor biomédico começou a se recuperar o que, por sua vez, acelerou o mercado de ações, o que deu uma sensação de recuperação, que então restaurou a confiança do consumidor para estimular uma recuperação de verdade! O Phalanx com certeza acabou com a recessão! Eu... eu acabei com a recessão! (BROOKS, 2006, p.58, trad. livre)

Nota-se que o sistema capitalista, que visa o lucro mesmo em situações catastróficas, parece ser a mais perfeita representação, em termos econômicos, da emergência do zumbi: ele canibaliza suas vítimas, transformando o que é vida em morte. $O$ frenesi consumista em torno do Phalanx em Guerra Mundial Z, portanto, ilustra uma nova leitura da alegoria capitalista presente no zumbi - em vez de escravo do trabalho, ele se torna escravo do consumo, pois "o zumbi agora representa o novo escravo, o trabalhador capitalista, mas também o consumidor, preso dentro de uma construção ideológica que assegura a sobrevivência do sistema." (LAURO \& EMBRY, 2008, p.99, trad. livre).

Uma das características primordiais do ser monstruoso consiste na personificação de um caráter dual (PAFFENROTH, 2006, p.7). Esse aspecto é evidente na combinação de duas criaturas, muito comum desde a mitologia clássica (o centauro, o 
Minotauro etc.) até monstros mais célebres da literatura de horror (o lobisomem). O zumbi também participa dessa ordem liminar que impera entre os monstros, mas sua força destrutiva vai para além de uma identidade dupla - até porque o zumbi seria a epítome da subjetividade zero. Os mortos-vivos podem servir como representação da permanência de um sistema capitalista que devora o homem, mas por outro lado ele corporifica a derrubada desse mesmo sistema: as convenções sociais e as estruturas de poder não têm como se sustentar em meio ao apocalipse zumbi. O zumbi, nessa perspectiva, é mais do que dual, ele é

distintamente oximorônico, ao mesmo tempo o produto vazio do capital, do trabalho ou até mesmo, de forma mais geral, da sociedade, e ao mesmo tempo uma força primitiva e animalesca pronta para aniquilar toda essa mesma organização. (BOLUK \& LENZ, 2011, p.147, trad. livre).

Guerra Mundial Z exemplifica a paradoxal complexidade do zumbi ao analisar a reestruturação da ordem social durante a invasão zumbi, especialmente nos Estados Unidos. A configuração classista que fundamenta a sociedade norte-americana sofre uma profunda mudança quando a ameaça zumbi força os indivíduos a priorizarem tarefas relacionadas diretamente a sua sobrevivência em detrimento do bem-estar ou entretenimento. Em um mundo à beira do colapso, a praticidade e a necessidade imediata são a pauta do dia. O ex-diretor do Departamento de Recursos Estratégicos dos EUA, Arthur Sinclair, explica a situação:

Você é um bem-sucedido advogado empresarial. Você passou a maior parte de sua vida revisando contratos, fechando negócios, falando ao telefone. Você é bom nisso, foi o que tornou você rico e o que permitiu a você contratar alguém para consertar a sua privada [...] Era assim que o mundo funcionava. Mas um dia não é mais assim. Ninguém precisa mais revisar contratos nem fechar negócios. O que precisam é de privadas funcionando. E de repente aquele serviçal é seu professor, talvez até mesmo o seu chefe. Para alguns, isso era mais assustador que os mortos-vivos. (BROOKS, 2006, p.140, trad. livre)

Percebe-se então que os zumbis, mesmo que indiretamente, causam uma mudança fundamental no tecido social norte-americano. Na narrativa de Guerra Mundial Z, o mundo como o conhecemos é destruído, mas outro (mais igualitário?) toma o seu lugar. E, de certa forma, os próprios indivíduos reconhecem o valor dessa nova forma de experimentar o capitalismo. Sinclair conclui que várias pessoas depois admitiram "ter mais satisfação emocional com seus novos empregos do que com qualquer coisa parecida com suas antigas profissões" (BROOKS, 2006, p.141, trad. livre).

Não é apenas em termos sócio-econômicos que o apocalipse zumbi altera as estruturas de poder em Guerra Mundial Z. Em termos de política internacional, as próprias noções de democracia, desenvolvimento e diplomacia são problematizadas quando as 
nações têm de lidar com uma ameaça que surge dentro de seus territórios. Uma das transformações mais marcantes (e sarcásticas) no contexto global pós-zumbi é a ascensão de Cuba como a maior potência mundial. A ilha comandada por Fidel Castro, na narrativa de Guerra Mundial Z, devido a sua geografia privilegiada e competente esquema de defesa, tornou-se um dos poucos lugares do mundo livre de mortos-vivos. Por causa disso, diz um personagem de origem cubana, vários refugiados especialmente vindos dos EUA chegavam ao país, "em grandes navios, aviões particulares ou em jangadas rudimentares, o que estampava um sorriso irônico em nossos rostos." (BROOKS, 2006, p.230, trad. livre). Esses refugiados, depois chamados de "Nortecubanos", serão responsáveis pela alavancada econômica de Cuba e seu rápido desenvolvimento. Mais uma vez, os zumbis servem de causa primeira para uma alteração no estado estabelecido, invertendo a posição de dominador e dominado.

Os atritos que cercam essa nova ordem mundial chegam ao ápice em uma conferência entre diversas nações que ocorre no USS Saratoga, o navio da marinha norte-americana que serve de sede flutuante para a Organização das Nações Unidas. Dentre os vários assuntos abordados no evento, um ponto importante foi o fato de os zumbis serem uma ameaça maior em países do norte, com períodos de inverno bem definidos, pois com o derretimento do gelo várias comunidades têm de enfrentar uma nova horda de mortos-vivos, tornando a guerra nessas regiões praticamente interminável. Em resposta a essa discussão, um delegado de um país "em desenvolvimento" antes da guerra afirma que, já que os países com esse tipo de problema eram os que se costumavam chamar de "Primeiro Mundo",

talvez essa seja a punição deles por explorar e roubar as "nações vítimas do sul". Talvez, ele disse, ao manter a "hegemonia branca" distraída com seus próprios problemas, a invasão dos mortos-vivos possa permitir que o resto do mundo se desenvolva "sem intervenção imperialista." Talvez os mortos-vivos tenham trazido mais do que apenas devastação para o mundo. Talvez, no final, eles tenham trazido justiça para o futuro. (BROOKS, 2006, p.266, trad. livre)

Nota-se no discurso acima, portanto, que há uma completa inversão no entendimento do zumbi a partir de uma perspectiva política e ideológica. De força anárquica causadora de destruição, o zumbi passa a ser visto como símbolo não só da igualdade, mas também do despertar de um sentimento de justiça. Para resolver questões insolúveis dos vivos, só mesmo sendo morto-vivo.

Para além da esfera de teorias de política internacional, das mudanças sociais e das estratégias de guerra, o zumbi se configura como o monstro ícone da contemporaneidade. Ele ressignifica a própria noção de identidade, levando-a a um estado de ontologia nula. Porém, através da emergência dos mortos-vivos na 
literatura norte-americana do início do século XXI, nota-se que o zumbi pode servir de alegoria para os mais diversos anseios e medos. Ele é uma página em branco onde são escritas não só as narrativas de aniquilação e morte, mas também de renovação e superação. Em sua (de)composição, o zumbi prescreve não só a ruína, mas também o alvorecer de diferentes formas de entender o homem e o mundo.

\begin{abstract}
One of the most popular monsters of the contemporary period, the zombie is composed as a privileged significant to capture the anxieties of the early 21st century. Originated in the travel narratives of Haitian explorers in the early 20th century, and then acquiring the status of major creature in recent horror cinema, the zombie has been serving as an allegory for American authors to explore discussions about the limits of civilization, the body and the notion of self. This work focuses on two essential novels which help to understand the zombie as a symbol of the (de) composition of the contemporary world. The first is Zone One, by Colson Whitehead, which shows the attempt to reconstruct New York City after it is infested by these gruesome creatures. The novel also introduces a very peculiar and complex variation of the zombie: the "straggler". The second work discussed in this article is World War Z, by Max Brooks, which delineates a mosaic of characters and narrates the events of a global war against zombies that nearly destroyed humanity. Both novels analyze, in their narratives, how the zombie problematizes notions of otherness, in that it is a creature devoid of subjectivity that, nevertheless, still holds traces of humanity. Furthermore, the living dead serve as an example of the concept of the "uncanny" (unheimlich), as devised by Freud. Thus, the present article aims to investigate the ascension of the zombie as a metaphor for the contemporary moment in U.S. literature, while discussing how this hideous monster serves as a representation of 21st century zeitgeist.
\end{abstract}

Keywords: zombie; monster; contemporary U.S. literature. 


\section{REFERÊNCIAS}

BISHOP, Kyle William. American Zombie Gothic: The Rise and Fall (And Rise) of the Walking Dead in Popular Culture. Jefferson: McFarland \& Company, Inc., 2010.

BOLUK, Stephanie \& LENZ, Wylie, eds. Generation Zombie: Essays on the Living Dead in Modern Culture. Jefferson: McFarland \& Company, Inc., 2011.

BROOKS, Max. World War Z: An Oral History of the Zombie War. London: Duckworth, 2006.

CHRISTIE, Debora \& LAURO, Sarah Juliet, eds. Better Off Dead: The Evolution of the Zombie as Post-Human. New York: Fordham University Press, 2011.

DELEUZE, Gilles \& GUATTARI, Felix. Anti-Oedipus: Capitalism and Schizophrenia. Minneapolis: University of Minnesota Press, 1983.

DREZNER, Daniel W. Theories of International Politics and Zombies. Princeton: Princeton University Press, 2011.

FASSLER, Joe. "How Zombies and Superheroes Conquered Highbrow Fiction." The Atlantic [online], Oct 182011.

Disponível em <http://www.theatlantic.com/entertainment/ archive/2011/10/how-zombies-and-superheroes-conqueredhighbrow-fiction/246847/> Acessado em 20 de julho de 2013.

FREUD, Sigmund. The Uncanny. London: Penguin Classics, 2003. GRANOFSKY, Ronald. The Trauma Novel: Contemporary Symbolic Depictions of Collective Disaster. New York: Peter Lang, 1995.

HALBERSTAM, Judith. Skin Shows: Gothic Horror and the Technology of Monsters. London: Duke University Press, 1995.

HERVEY, Ben. Night of the Living Dead. New York: Palgrave Macmillan, 2008.

LAURO, S. J., \& EMBRY, K. "A Zombie Manifesto: The Nonhuman Condition in the Era of Advanced Capitalism." boundary 2, v. 35, n. 1, p. 85-108, 2008.

LEVERETTE, Marc \& McINTOSH, Shawn. Zombie Culture: Autopsies of the Living Dead. Plymouth: Scarecrow Press, Inc., 2008. MOREMAN, Christopher M. \& RUSHTON, Cory James, eds. Zombies Are Us: Essays on the Humanity of the Walking Dead. Jefferson: McFarland \& Company, Inc., 2011.

PAFFENROTH, Kim. Gospel of the Living Dead: George Romero's Visions of Hell on Earth. Waco: Baylor University Press, 2006.

RUSSELL, Jamie. Zumbis: O livro dos mortos. São Paulo: Leya, 2010. SCOTT, Niall, ed. Monsters and the Monstrous: Myths and Metaphors of Enduring Evil. New York: Rodopi, 2007. 
SEABROOK, William. The Magic Island. New York: Paragon House, 1989.

ST. JOHN, Warren. "Market for Zombies? It's Undead (Aaahhh!)." The New York Times [online], March 26, 2006. Disponível em <http:// www.nytimes.com/2006/03/26/fashion/sundaystyles/26ZOMBIES.html?pagewanted=all\&_r=0 $>$ Acessado em 21 de julho de 2013.

WHITEHEAD, Colson. Zone One. New York: Doubleday, 2011. 